from lambs aged up to four hours and (2) Depressed heat production due to starvation in older lambs. All lambs are susceptible to hypothermia but high risk lambs include twins and triplets, lambs which suffer hypoxia during birth, lambs from ewes in poor condition and lambs from very young or very old ewes. Prevention of hypothermia depends on good nutrition during pregnancy and a high standard of management at lambing time. Effective treatment of hypothermia depends on early detection of the condition, administration of glucose to lambs aged five hours of more, rewarming in warm air and careful aftercare.

\title{
The effect of ACTH on parturition as defence mechanism stimulator in sows
}

\author{
J.B. LUDVIGSEN \\ National Institute of Animal Science \\ Rolighedsvej 25, 1958 Copenhagen V, Denmark
}

Injection of a long acting ACTH preparation on the 140th day of pregnancy reduces parturition time by 21 and 23 p. 100 in Danish Landrace and Piétrain sows respectively. The parturition time of the Piétrain sows was about 20 p. 100 longer than in the Danish Landrace.

The difference in parturition time between the two breeds, and the shortening effect of ACTH is discussed from general stress susceptibility points of view : the Piétrain having a higher incidence of PSE, PSS and Halothane positivity than Danish Landrace, caused by an impaired genetic ability to mobilize adaptive endocrine systems, especially the pituitaryadrenal cortical axis at time of parturition.

ACTH stimulates the adaptive system by way of an increased release of adrenal cortical steroids. One of the effects of an increase in circulating adrenal cortical hormones, is a stimulation of uterine contractions.

The mode of action of adrenal cortical hormones in the defence mechanism of the organism against external as well as internal stress situations, in the present case parturition, is discussed.

\section{Effect of $\mathbf{T}_{2}$ Fusarium toxin on adrenocortical function and immune response of growing pigs}

\author{
P. RAFAI and S. TUBOLY \\ University of Veterinary Science \\ H - 1400 Budapest, P.O. Box 2, Hungary
}

Six Hungarian Large White $\times$ Duroc $\mathrm{F}_{1}$ pigs fed $\mathrm{T}_{2}$ toxin at $5 \mathrm{mg} / \mathrm{kg}$ dietary level for 25 days after weaning at 28 days of age were examined for weight gain, adrenocortical activity and main cell-mediated and humoral immune reactions by comparison to 6 control pigs of the same age and breed.

Toxin treatment accounted for $49-77$ p. 100 feed refusal, and consequent marked depression of weight gain. The average daily toxin ingestion was assessed as $1.27 \mathrm{mg}$.

$\mathrm{T}_{2}$ also depressed the total leucocyte count, but did not give rise to leucocytopenia during the 25 days of treatment.

The adrenocortical activity of $T_{2}$-treated pigs increased significantly over the control. 
In vitro testing of blast transformation, immune rosette formation, and IF-detectable IgG-positive cell counts indicated a $40-50$ p. 100 decrease of immunological responsiveness relative to the control. Toxin neutralizing titres to necrotic enteritis/NE/vaccine were in fact significantly lower in the sera of $T_{2}$-treated pigs.

In the given conditions of experiment, $T_{2}$ developed a distinct immunosuppressive action in the early phase of immune induction in growing pigs by interfering with the function of both T- and B-lymphocytes.

\title{
Erythrocyte glutathione peroxidase (GSH-Px) polymorphism in Finnsheep
}

\author{
F. ATROSHI *, S. SANKARI, S. OETERBERG and M. SANDHOLM \\ Department of Pharmacology and Toxicology (*)/Department of Biochemistry \\ College of Veterinary Medicine, Helsinki 55, Finland \\ and Department of Animal Breeding, Agricultural Research Centre, Vantaa, Finland
}

Erythrocyte glutathione peroxidase (GSH-Px) was studied in 200 Finnsheep. The concentration of GSH-Px varied between 500 to $1800 \mu \mathrm{kat} / 1$ red cells and the distribution revealed a bimodality despite the same diet and selenium intake. The peroxidase activity of the sheep erythrocytes was classified high if it was $>1000 \mu \mathrm{kat} / \mathrm{l}$ or low if it was $<1000 \mu \mathrm{kat} / \mathrm{l}$. Inheritance studies of GSH-Px types revealed that they are controlled by a pair of autosomal genes, the genes for GSH-Px high being dominant to the genes for GSH-Px low. These two groups of sheep were then compared for other blood parameters and production characteristics. It is proposed that the low GSH-Px may represent an adaptation to low selenium intake.

SESSION II

PROBLEMES D'ÉLEVAGE SOUS LES TROPIQUES

\section{Cattle production in the tropics and improvement through breeding}

\author{
J. RENDEL \\ Animal Production and Health Division \\ Food and Agriculture Organization of the United Nations \\ Via delle Terme di Caracalle, 00100 Rome, Italy
}

Results from breeding and improving dairy and beef cattle in the tropics are reviewed. It is concluded that for improved dairy production, climate per se is no serious constraint to the use of European-type cattle in tropical highlands or in dry, hot areas provided that management is good. In hot, humid areas, European-type cattle do not adapt well, and local well-adapted breeds or crosses should be used. Suitable breeding policies are outlined. Under conditions of smallholder production, the extensive system with crossbred cattle, once-a-day milking and calf suckling has a role to play. Beef production is generally carried 